\author{
Asian Journal of \\ Medical and Biological Research \\ ISSN 2411-4472 (Print) 2412-5571 (Online) \\ www.ebupress.com/journal/ajmbr
}

\title{
Article \\ Isolation, identification and pathogenicity of fungal organisms causing postharvest rot of sweet oranges, cucumber and lettuce in Sharada Market, Kano State-Nigeria
}

\author{
Ya'u Mukhtar $^{1 *}$, Maryam Adamu Muhammad ${ }^{2}$, Safiyya Maiwada Zubairu ${ }^{1}$, Aisha Muhammad Galalain ${ }^{1}$ and \\ Umar Muazu Ahmad ${ }^{1}$ \\ ${ }^{1}$ Department of Plant Biology, Faculty of Life Sciences, Bayero University, Kano, PMB 3011, Kano, Nigeria \\ ${ }^{2}$ Department of Integrated Science, Sa'adatu Rimi College of Education, Kumbotso, Kano, Nigeria \\ "Corresponding author: Ya'u Mukhtar, Department of Plant Biology, Faculty of Life Sciences, Bayero \\ University, Kano, PMB 3011, Kano, Nigeria. Phone: +234806266214; E-mail: ym1700003.mpb@buk.edu.ng
}

Received: 16 September 2019/Accepted: 04 October 2019/ Published: 31 December 2019

\begin{abstract}
Isolation, identification and pathogenicity of fungal organisms responsible for the postharvest spoilage of sweet oranges, cucumber and lettuce at Sharada market in Kano metropolis, Nigeria was carried out in the present study. Samples showing symptoms of rot were collected from the retailers in the market and conveyed to the laboratory using polyethene bags. Small portion from rotten parts were cut and surface sterilized in $1 \%$ of Sodium hydrochloride and rinsed in several changes of sterile distilled water. They were plated on Potato Dextrose Agar (PDA) and observed for fungal growth. Identification was done macroscopically and microscopically. For pathogenicity test, healthy sweet oranges, cucumber and lettuce were plugged with pure cultures of the fungal isolates, thus, frequency of occurrence and disease severity of the pathogen were evaluated. Seven fungi namely Rhizopus spp., Aspergillus flavus, Mucor spp., Aspergillus fumigatus, Aspergillus niger, Fusarium oxysporum, Rhizoctonia spp. and Fusarium oxysporum were isolated. Severity of decay ranged from $6.39-46.15 \%$ for all fungal isolates, while the controls showed 0\%. Pathogenic microorganisms on fruits and vegetables are a potential health hazard to man and animals following ingestion. Proper handling from the farm as well as during storage and the avoidance of mixing of diseased ones with the healthy ones were identified as important factors in preventing loss and health complication at the event of consumption. The use of suitable chemical treatment of the orange is also recommended as means of reducing economic loss due to fungal pathogens.
\end{abstract}

Keywords: mycological studies; sweet oranges; cucumber; lettuce; isolation; identification

\section{Introduction}

Post-harvest diseases destroy almost about $10-30 \%$ of the total crops yield of crops especially the perishable ones. In developing countries, this diseases account for more than 30\% lost in crop yields (Agrios, 2005; Kader, 2002). Fruits and vegetables are highly perishable products and the quality is affected by post- harvest handling, transportation, storage and marketing. The improper handling, packaging, storage and transportation may result in decay and production of microorganism which become activated due to change in physiological state of the fruits and vegetables (Pusey and Wilson, 1984). As a result of their low $\mathrm{pH}$, higher moisture content and nutrient composition, fruits are very susceptible to attack by pathogenic microorganism, which in addition to also make them unfit for consumption thereby producing mycotoxin (Philips, 1998; Moss, 2002; Stinson et al., 1981). International agencies that monitor world food resource have acknowledged that one of the most feasible options for meeting future food needs is reductions of post- harvest losses in our cultivated crops (Kelman, 1984). Thus, careful post -harvest handling is the major but often neglected step towards offering a greater volume of nutritious food to plant and to prevent loss between harvesting and consumption. Fungi are the most important and prevalent pathogens infecting wide range of host plants thereby causing destructive and 
economically important losses of most fresh fruit including sweet oranges and vegetables like lettuce and cucumber during storage and transportation than bacteria (Sommer, 1985).

Losses caused by post-harvest diseases are generally greater than realized because the value of fresh fruits and vegetables increases several fold while passing from the field to the consumer (Eckert and Sommer, 1997). Postharvest losses in orange alone are estimated between 10-30\% annually despite the use of modern storage facilities and techniques (Harvey, 1978).

Sequel to that, since microorganism (pathogens) are mostly the casual agents of deterioration of this important fruit and vegetables i.e. sweet oranges, cucumber and lettuce, after harvest all over the nation, thus the need to identify the specific pathogens that causes this problem is highly imperative for proper selection of suitable protection and control strategy for sustainable production of fruit and vegetables in order to ensure food availability and its security globally.

\section{Materials and Methods \\ 2.1. Samples collection}

Samples of sweet orange, cucumber and lettuce showing signs of deterioration and healthy ones were randomly obtained from Sharada market in Kano State Nigeria. The samples were later transported to the laboratory using polyethene bag and kept unwashed before the practical. The healthy ones were preserved for the purpose of pathogenicity test.

\subsection{Sterilization}

All apparatus involved in this experiment were decontaminated appropriately. Materials such as agar were aseptically sterilized in an autoclave at $121^{\circ} \mathrm{C}$ for 15 minutes, wire loop was also sterilized in flame until red hot and allow to cool before using and $1 \%$ sodium hypochloride was used to wiped the top work place to prevent contamination (Uker and Chiejina, 2012).

\subsection{Preparation of culture media}

Potato Dextrose Agar (P.D.A) used for culturing fungi was prepared according to the manufacturers' instruction and autoclave at $121^{\circ} \mathrm{C}$ for 15 minute.

\subsection{Isolation of fungi}

The isolation techniques employed by Chiejina (2008) was adopted in the present study. Thin sections $(2 \mathrm{~mm}$ diameter) was cut from the periphery of the deteriorated samples and sterilized with $1 \%$ sodium hypochloride for two minute and rinsed in several changes of distilled water. The thin section was put into petri dish containing PDA medium amended with antibiotics (streptomycin), inverted and incubated at $37^{0} \mathrm{C}$ room temperature for 3 days. The pure/axenic culture were obtained by several transfer of colony growth from PDA plates aseptically i.e. (Sub-culturing until axenic culture was obtained).

\subsection{Determination of percentage of fungal occurrence}

This was done to determine the frequency of occurrence of the different fungal isolates. Isolations were made on different diseased oranges, lettuce and cucumber and cultured differently. The number of occurrence for each of the isolates were recorded, calculated and expressed as percentage.

Percentage of occurrence $=\frac{X}{N} \times \frac{100}{1}$

Where;

$\mathrm{X}=$ Total number of individual organism in all the fruits

$\mathrm{N}=$ Total number of the entire organisms in all the fruits screened.

\subsection{Determination of severity of rot}

To assess the severity of rot cause by the pathogens, apparently healthy samples (sweet orange, cucumber and lettuce) were weighed and surface sterilized. A hole is created on each sample and mycelia mat was introduced, put back the cover and sealed with jelly. For each of these samples, a control was put in place i.e. the sample with no mycelia mat for the purpose of comparison. The resultants were incubated for 4 days after which each fruit or vegetable were collected and the extent of rot (Severity Infection) was determined according to the method described by Kassim (1986), i.e. scooping of the rotted portion and taking the final weight of the individual samples (sweet orange, lettuce, and cucumber).

Severity $(\%)=\frac{W}{w}-\mathrm{w}$ X 100

Where; 
$\mathrm{W}=$ Initial weight of the healthy samples

$\mathrm{w}=$ Weight of the rotted portion

\subsection{Pathogenicity test}

Pathogenicity test was carried out according to the procedures described by (Okibo et al., 2009). Apparently healthy samples of fruits and vegetables were washed in sterile distilled water and surface sterilized with $1 \%$ sodium hypochloride solution. The fruit and vegetable were cut using sterile razor blade and then the mycelia mat of pure isolated culture were introduced into an open cut, replaced with the core, then sealed with jelly and incubated for 24-72 hours. For each of these samples, healthy ones that were not inoculated are kept as control. Pure cultures were identified according to the methods of Alexopoulos et al., (2002) and Barnett and Hunter, (1999). The symptoms were identical to those of naturally infected samples. Morphological characteristics of conidia and mycelia of the fungi that were re-isolated from inoculated fruits confirmed Koch's postulates.

On establishment of diseases symptoms of rot, inoculums from this sample were taken and cultured, pure cultures were identified according to (Bernett and Hunter, 1999; Alexopolous et al., 2002).

\subsection{Identification of fungi}

Identification was done macroscopically and microscopically. For macroscopic identification, colony characteristics such as appearance, change in medium colour and growth rate were observed on the petri plates. For microscopic identification, a thin smear of fungi isolates from 5-7 day old cultures were inoculated aseptically on a clean glass slide using a sterile inoculating loop. A drop of lactophenol cotton blue was added and the mixture was covered with a cover slip and viewed under X40 objective lens of the light microscope. Shapes of the conidia and conidiophores were taken note of. These features were matched with standards described by Barnett and Hunter (1972) and Broth (1971) as reported by Liamngee et al. (2015).

\section{Results}

The present investigation revealed that Rhizopus spp. (43.3\%), Aspergillus flavus (25.0\%) and Mucor spp. (31.7\%) were responsible for the postharvest rot of sweet oranges at Sharada market in Kano metropolis (Table 1). Likewise, Aspergillus fumigatus (46.15\%), A. niger (15.38\%), Fusarium oxysporum (38.46\%) were also the fungal isolates responsible for the postharvest rot of cucumber at Sharada market in Kano metropolis. Similarly from Table 1, Fusarium oxysporum (33.33\%) and Rhizoctonia spp. (66.67\%) were also responsible for the postharvest rot of lettuce in the study area respectively. Pathogenicity tests conducted on these particular healthy samples further confirmed that, these fungal isolates were the causal agents of the rot.

A. flavus appears as greenish surrounded by whitish hairy mass on PDA media. Microscopically, the conidia head is radiated and borne directly on the vesicle conidiophore that is hyaline. Aspergillus fumigatus appears dark-green in colour and whitish mass of growth at the margin, conidial head is uniseriate, and conidiophore is short, smooth-walled and conical terminal head. A. niger appeared as dark hairy on PDA media, the conidial head is globose, biseriate with philiades, conidiophore are smooth-walled and hyaline. Fusarium oxysporum changes colour from pink to cream on PDA media and microscopically produces macro-conidia. The macroconidia is hyaline (transparent), the spores ranging from two to several in length.

Likewise, colonies of Mucor spp. grown on PDA were white at first turning brownish to gray with age and become heavily speckled with the appearance of sporangia. Rhizopus appearance on PDA is characterized by the presence of stolons and pigmented rhizoids, the fornation of sporangiophores, singly or in groups from nodes directly above the rhizoids, and columellate, multispored, generally globose sporangia. Microscopically, hyphae is broad, not or scarcely septate, rhizoids and stolon present, sporangiophores brown and ovoid, solitary or in tufts on the stolon, diverging from the point at which the rhizoids are formed. Rhizoctonia appears colorless when young but became brown colored as they grow and matured. The mycelium consists of hyphae partitioned into individual cells by a septum containing a doughnut shaped pore.

Table 1. Frequency of occurrence of various fungal isolates in diseased samples.

\begin{tabular}{lll}
\hline Samples & Fungal Isolates & Frequency $(\%)$ \\
\hline Sweet Orange & Rhizopus spp. & 43.30 \\
& Aspergillus flavus & 25.00 \\
Cucumber & Mucor sp. & 31.70 \\
& Aspergillus fumigatus & 46.15 \\
Lettuce & Aspergillus niger & 15.38 \\
& Fusarium oxysporum & 38.46 \\
& Fusarium oxysporum & 33.33 \\
\hline
\end{tabular}


Table 2 below indicates the severity of rot of the samples caused by each fungal isolate. The results showed that, the highest severity of rot was caused by Fusarium oxysporum (46.15\%) and Rhizoctonia spp. (25.00\%) both in lettuce sample. However, lower severity of rots was caused by Mucor spp. (6.39\%) and Aspergillus fumigatus $(8.53 \%)$ both on cucumbers respectively.

Table 2. Severity of rot on healthy samples inoculated with isolated fungi.

\begin{tabular}{llll}
\hline Samples & Fungal Isolates & Frequency (\%) & Rating \\
\hline Sweet Orange & Rhizopus spp. & 20.98 & Mild \\
& Aspergillus flavus & 12.60 & Mild \\
Cucumber & Mucor sp. & 6.39 & Low \\
& Aspergillus fumigatus & 8.53 & Low \\
& Aspergillus niger & 16.55 & Mild \\
Lettuce & Fusarium oxysporum & 20.63 & Mild \\
& Fusarium oxysporum & 46.15 & Moderate \\
& Rhizoctonia spp. & 25.00 & Mild \\
\hline
\end{tabular}

\section{Discussion}

The present investigation was able to isolate and identified a total of seven fungal pathogens responsible for the postharvest rot of sweet oranges, cucumber and lettuce traded in Sharada market in Kano metropolis. This indicated that the pathogens isolated could grow and survive in this particular fruit and vegetables samples which is probably due to the fact that these perishable products contain some nutrients suitable for the growth of pathogens. The spoilage of the fruits and vegetables during post-harvest storage is due to infection by these microorganisms which might have gained entry through stomata openings, growth cracks or surface injuries (Wills et al., 1981). These pathogens also gained entry through injuries caused by rough handling, poor road and storage facilities (Liu and Ma, 1983).

Fruits may be infected when green and small but do not show any marked lesion until they begin to ripen, so the disease mostly affects only ripen fruits. At first, infected fruits show small slightly sunken water soaked spots. These spot later enlarge, become darker and brown in colour. Sunken and have concentric rings until the entire fruit is consumed by the rot (Ukeh and Chiejina, 2012). Losses caused by post-harvest diseases have increased recently than generally realized because the value of fruits and vegetables has increased (Eckert and Sommer, 1967). Splittstoesser, (1987) reported that species of the genera Penicillium, Aspergillus and Mucor are common post-harvest fungi. Also Aspergillus niger, Mucor spp. and Penicillium digitatum were found to cause rot of cassava (Okigbo et al., 2009) and these were implicated as pathogen when tested on healthy products.

The most serious postharvest diseases are those that cause rapid and extensive breakdown of crops that are high in moisture content and nutrients. It has been estimated by Liu and Ma (1983) that, 30\% of all fruits rots are caused by a species of Penicillium. In this work, Rhizoctonia spp., Aspergillus fumigatus and Rhizopus spp. are the most virulent pathogens. The occurrence of these organisms may be attributed to their ability to produce resistant spores, as reported by Faweette and Lee, (1926) that spores of Aspergillus are more resistant to high temperature. And in conjunction to this, Aspergillus species have been implicated in the spoilage of fruits and vegetables in Nigeria (Uzuegbu and Emifoniye, 1984). Fusarium is known to be moisture loving and tends to occur in fruits with relatively high moisture content, such as oranges. In consonance to this work, Bukar et al. (2008) isolated Aspergillu spp. (32.5\%) out of the total samples used when studying fungal species that causes postharvest spoilage of sweet oranges at Na'ibawa 'Yan Lemo Market in Kano. However, in this work, Aspergillus fumigatus (46.15\%), Aspergillus flavus (25\%) and Aspergillus niger (15.38) were isolated.

Furthermore, Most Fusarium species are soil borne fungus that causes disease to varieties of fruits and vegetables e.g. crown and foot rot of squash and pumpkin which is caused by Fusarium specie called $F$. solani. Similarly most Aspergillus species are saprophytic pathogenic fungus, while some are cosmopolitan in distribution (Ramirez et al., 2012) e.g. A. flavus overwinters in the soil and appears as propagules and decaying matter either as mycelia or sclerotia and later become pathogen to subsequent plant when planted in the field (Hedayati et al., 2007).

The pathogenicity test result revealed that all the fungal isolates identified had the ability to cause infection in healthy fruit and vegetables samples, though at various percentages of severity. The healthy samples showed symptoms of rot after three (3) days of inoculation with fungal mycelia. Morphological and microscopic characteristics were compared with initial cultures after re-isolation and were found to be similar. The controls (healthy sweet oranges, cucumber and lettuce inoculated with sterile PDA only) showed no symptom of rot. The 
ability of the fungal isolates to cause infection in healthy samples was due to the fact that the pathogens are able to utilize the nutrients of the fruits as a substrate for growth and development (Liamngee et al. 2015).

The presence of the fungi or their resistant spores is most likely to have originated from the farms where the fruits were harvested and some from the stores due to horizontal contamination by the already spoilt fruits Bukar et al. (2009). Jay (2003) observed that most spoilage organisms may be present on fruits and vegetables from the farm, during harvest operations, and this may result in postharvest contamination and spoilage of these fruits and vegetables. More so, Kator et al. (2018) opined that, fruits due to their low pH, high moisture content and nutrients composition are very susceptible to attack by pathogenic fungi which in addition to causing rots, also make them unfit for consumption by producing mycotoxins. The contamination of the orange fruits, cucumber and lettuce vegetables by these fungal pathogens could be as a result of poor handling practices in their production chain, storage conditions, distribution and changing physiological state of the fruits (Beuchat, 2006). Precautionary measures should be put in place to ensure that this problem is tackled right from the farm, because reducing post-harvest loss of fruits that have already been produced is more sustainable and environmentally sound than increasing production areas to compensate for these losses (Kader, 2002).

\section{Conclusions and Recommendations}

The findings of the present study was able to unveiled the spoiled sweet oranges were mainly attacked by Rhizopus spp., Aspergillus flavus, and Mucor spp. However, cucumber rot was as a result of attack by Aspergillus fumigatus, Aspergillus niger and Fusarium oxysporum while lettuce was contaminated by Rhizoctonia spp. and Fusarium oxysporum respectively. Presence of these fungi in these samples, most especially Aspergillus spp. (as it records highest incidence of encounter among the samples) poses a serious threat to health of consumers as the organism could produce mycotoxins, which are lethal when consumed. Most of the fungi isolated were observed to be able to re-infect healthy oranges within short time and this poses a serious economic threat to sellers of oranges in Sharada market. No doubt, this subsequent spoilage caused by these fungi should be checked in order to avert serious economic loss and possible health hazards as well. Lastly, extracts from herbal species should be employed as antifungal agents against these identified fungal pathogens and this can serve as a bed rock for pharmacological researches towards development of antifungal drugs from plants origin.

\section{Conflict of interest}

None to declare.

\section{References}

Agrios, G.N. 2005. Plant pathology. Academic Press.

Alexopoulos, C.O, Mims, C.W and Blackwell, M. 2002. Introductory Mycology.

Barnett HL and BB Hunter. 1972. Illustration genera of imperfect fungi, 3Rd edition, Burgess Publing Co. Minnesoth, USA. 273.

Barnett HL and BB Hunter, 1999. Illustrated Genera of Imperfect Fungi, (4th edition). The American Phytopathological Society . St. Paul, Minnessota, USA, 218 pp.

Beuchat LR, 2006. Vectors and Conditions for preharvest contamination of fruits and vegetables with pathogens capable of causing enteric disease. Br. Food J., 108: 38-53.Broth C, 1971. The genus Fusarium, Survey, UK: CMI, Kew. 237-238.

Bukar A, MD Mukhtar and S Adamu, 2009. Isolation and identification of postharvest spoilage fungi associated with sweet oranges (Citrus sinensis) traded in Kano Metropolis. Bayero Journal of Pure and Applied Sciences, 2: $122-124$.

Chiejina NV, 2008. Mycoflora of some salad vegetables. Bio-Research, 6: 392-395.

Eckert W and NF Sommer, 1967. Control of diseases of dirt and vegetables by post-harvest treat ltd. Ann. Rev. Plant Pathol., 5: 391-432.

Harvey Js.M, 1978. Reduction of Losses in Fresh fruits and vegetables. Ann. Rev. Phypath., 16: 321-341.

Jay JM, 2003. Microbial Spoilage of Food. Modern Food Microbiology. 4th ed. Chapman and Hall Inc. New York. pp. 187-195.

Kader AA, 2002. Post-harvest Technology of Horticultural crops. University of California, Agriculture and Natural Resources. 535 pp.

Kassim MY, 1986. Chemical control of post-harvest diseases of potato. Indian Phytopath., 2: 342-344.

Kator L, AC Iheanacho and KP Aloho (2018) Isolation, identification and pathogenicity of fungal organisms causing postharvest spoilage of tomato fruits during storage. Annual Research \& Review in Biology, 26:1-7. 
Kelman A, 1984. Postharvest pathology of fruit and vegetable. PP 1-3; In Post-harvest losses in perishable crops (ED): H.E Moline University of California Agricultural Experimental Station Bulletin.

Liamngee K, MU Akomaye and JK Okoro, 2015. Efficacy of some botanicals in the control of fungi causing postharvest rot of yam in Katube Market, Obudu, Nigeria. IOSR Journal of Pharmacy and Biological Sciences, 10: 33-41.

Liu MS and PC Ma, 1983. Post-harvest problems of vegetables and fruits in the tropics and subtropics. Asian Vegetable Research and Development Center.

Mossi MO, 2002. Mycotoxin review 1. Aspergillus and Penicillium. Mycologist, 16: 116-119.

Okigbo RN, P Ramesh and CT Achusi, 2009. Post-harvest deterioration of cassava and its control using extracts of Azadirachta indica and Aframomum melegueta. E-Journal of Chemistry, 6: 1274-1280.

Phillips DJ, 1998. Mycotoxin as a post- harvest problem. Pp.50-54 in: post-harvest loses in perishable crops. (Ed): H.E Moline Agricultural Experiment Station, University of California Berkeley Publications, NE.

Pusey PL and CL Wilson, 1984. Post-harvest biological control of stone fruit brown rot by Bacillus subtilis. 68: 753-756.

Sommer NF, 1985. Strategies for control of post -harvest disease of selected commodities. In: Post harvest technology of Horticultural crops. University of California. pp. 83-98

Splittstoesser DF, 1987. Fruits and fruit Products. pp. 101-128. In: Food and Beverage Mycology. Beuchat, L. (ed). Van Nostrand Reinhold, New York. 591pp.

Stinson EE, SF Osman, EG Heisler, J Sciliano and DD Bills, 1981. Mycotoxin production in whole tomatoes, apples, oranges and lemons. J. Agric. Food Chem., 29: 790-792

Ukeh JA and NV Chiejina, 2012. Preliminary investigation of the cause of post -harvest fungal rot of tomato. Journal of Pharmacy and Biological Science, 5: 36-39.

Uzuegbu JO and AT Emifoniye, 1984. Post harvest fungal spoilage of some Nigerian fruit and vegetables. Food Journal, 2: 153 - 155.

Wills RH, TH Lee, D Graham, WB Mcglassom and EG Hall, 1981. An Introduction to the physiology and handling of fruits and vegetables. London. NY. 432 pp. 